\title{
A Non Double-Couple Earthquake in a Subducting Oceanic Crust of the Philippine Sea Plate
}

\author{
Nobuo Hurukawa ${ }^{1, *}$ and Masajiro Imoto ${ }^{2}$ \\ ${ }^{1}$ International Institute of Seismology and Earthquake Engineering, \\ Building Research Institute, Tsukuba 305, Japan \\ ${ }^{2}$ National Research Institute for Earth Science and Disaster Prevention, \\ Tsukuba 305, Japan
}

\begin{abstract}
A non double-couple earthquake was found in an oceanic crust of the Philippine Sea plate subducting into the mantle in the Kanto district, central Japan. Its magnitude and focal depth are 4.6 and $57 \mathrm{~km}$, respectively. This subducting oceanic crust consists of low-density gabbro or basalt at depths shallower than about $60 \mathrm{~km}$, while it consists of high-density eclogite to which gabbro transformed at depths deeper than about $60 \mathrm{~km}$. The non double-couple earthquake occurred at this density boundary in the oceanic crust. Since the first motion of seismic $P$ waves is predominantly dilatational and shows volume contraction, we consider that this event was probably caused by a sudden phase transformation from gabbro to eclogite. Its predominant frequency implies that this phase transformation occurred instantaneously in the metastability field. Since this event emanated not only compressional waves but also shear waves, we conclude that the sudden volume contraction triggered a double-couple earthquake immediately. This interpretation is supported by the aftershock distribution and the P-wave first-motion distribution of an eyeball type, which has only one cone on the focal sphere.
\end{abstract}

\section{Introduction}

The subduction of the Philippine Sea (PHS) and Pacific (PAC) plates beneath the Kanto district causes many earthquakes in a depth range of 40-80 km (Kasahara, 1985; Nakamura and Shimazaki, 1981; Okada and Kasahara, 1990; Ishida, 1992). Almost all of them occur in oceanic crusts of the subducting PHS and PAC plates (Hurukawa and Imoto, 1990, 1992; Hori, 1990). Using data observed by a network of the National Research Institute for Earth Science and Disaster Prevention (NIED) (Hamada et al., 1985), Hurukawa and Imoto (1992) studied southwestern Ibaraki earthquakes at depths of 30 to $80 \mathrm{~km}$ in the Kanto district to obtain fine structure of the plate boundary between the PHS and overriding Eurasian (EUR) plates. They found a low-velocity layer with a thickness of about $4 \mathrm{~km}$ between the EUR and PHS plates by analyses of focal mechanisms of microearthquakes and a velocity in this layer. Then Hurukawa and

Received April 9, 1993; Accepted September 3, 1993

* To whom correspondence should be addressed. 
Imoto (1992) concluded that the low-velocity layer is an oceanic crust that exists at the top of the subducting PHS plate.

Hurukawa and Imoto (1992) also found a non double-couple earthquake of Feb. 10, 1987, of which magnitude and focal depth are 4.6 and $51 \mathrm{~km}$, respectively. Since it occurred at the boundary between low- and high-velocity subducting oceanic crusts, they suggested that it is probably a gabbro-eclogite transformation earthquake. In this paper, we study the source mechanism of this earthquake in detail.

\section{Hypocenters and Focal Mechanisms of Kinugawa-Cluster Earthquakes}

The focal depth of the non double-couple earthquake determined by Hurukawa and Imoto (1992) is $51 \mathrm{~km}$ and is about $10 \mathrm{~km}$ shallower than those determined routinely by the NIED or Japan Meteorological Agency (JMA). This difference is caused by differences of assumed velocity structures and stations used. Since we must compare our results with previous works, we relocate earthquakes changing a velocity model and a number of stations of the NIED to make a focal depth of the event about $60 \mathrm{~km}$. Using a method of modified joint hypocenter determination (Hurukawa and Imoto, 1992), we analyzed 63 Kinugawa-cluster earthquakes that were relocated by Hurukawa and Imoto (1992) with magnitude 3.0 or greater in the southwestern Ibaraki Prefecture, the Kanto district. Assuming the velocity structure shown in Table 1, we use 39 stations of the NIED shown in Fig. 1 in our relocation. Figure 2 shows relocated hypocenters of the Kinugawa-cluster earthquakes. Their focal depths are in average about $5 \mathrm{~km}$ deeper than those in Hurukawa and Imoto (1992). The focal depth of the non double-couple earthquake is $57 \mathrm{~km}$.

Since hypocenters are nearly same as those determined by Hurukawa and Imoto (1992), we use fault-plane solutions obtained by Hurukawa and Imoto (1992) as it is, except two solutions shown in Fig. 3. Fault-plane solutions of 25 earthquakes in the Kinugawa cluster are shown in Figs. 7 and 10 of Hurukawa and Imoto (1992). Earthquakes denoted by solid circles in Fig. 2 are thrust events with $P$ axes in NW-SE direction and which have low-angle nodal planes dipping northward. Almost all events of this type occurred at depths shallower than $55 \mathrm{~km}$ in the southeastern part of the

Table 1. P-wave velocity model.

\begin{tabular}{cccc}
\hline Layer number & $\begin{array}{c}\text { Velocity } \\
(\mathrm{km} / \mathrm{s})\end{array}$ & $\begin{array}{c}\text { Thickness } \\
(\mathrm{km})\end{array}$ & $\begin{array}{c}\text { Depth to layer top } \\
(\mathrm{km})\end{array}$ \\
\hline 1 & 5.600 & 4.0 & 0.0 \\
2 & 6.000 & 16.0 & 4.0 \\
3 & 6.600 & 10.0 & 20.0 \\
4 & 7.800 & 10.0 & 30.0 \\
5 & 7.827 & 10.0 & 40.0 \\
6 & 7.854 & 10.0 & 50.0 \\
7 & 7.881 & 10.0 & 60.0 \\
8 & 7.908 & 10.0 & 70.0 \\
9 & 7.935 & 10.0 & 80.0 \\
\hline
\end{tabular}




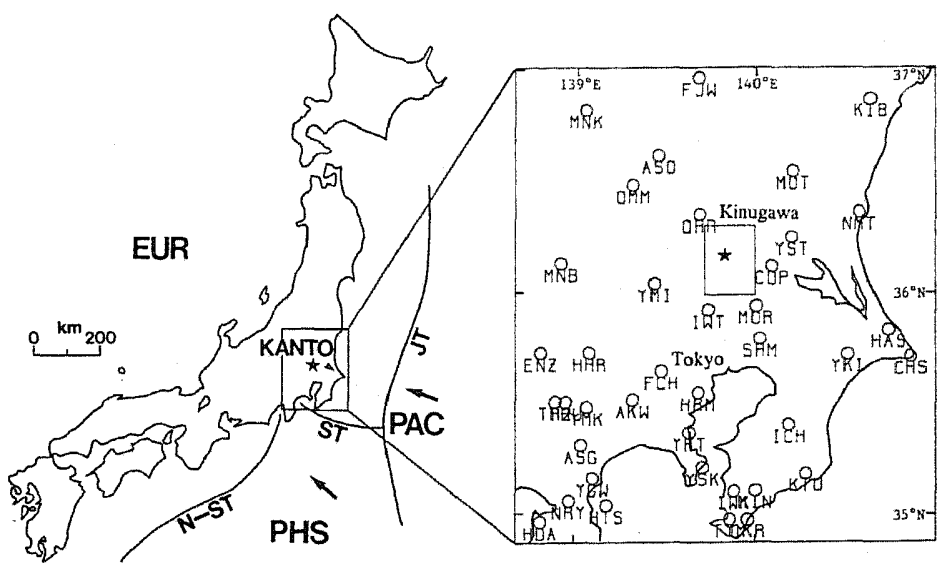

Fig. 1. Observational stations of the NIED used for hypocenter determination. Epicentral region of analyzed earthquakes is shown by the square. Asterisks represent the epicenter of the non double-couple earthquake. Arrows show directions of plate motions against the Eurasian plate. EUR, Eurasian plate; PAC, Pacific plate; PHS, Philippine Sea plate; JT, Japan trench; ST, Sagami trough; N-ST, Nankai-Suruga trough.

Kinugawa cluster. Since slip vectors and low-angle nodal planes of these earthquakes are parallel to a direction of relative motion of the EUR and PHS plates and a seismic layer, respectively, Hurukawa and Imoto (1992) concluded that these earthquakes occurred in the low-velocity oceanic crust of the subducting PHS plate. On the other hand, earthquakes deeper than $55 \mathrm{~km}$ in the northwestern part of the Kinugawa cluster show different mechanisms. Mechanisms of deeper earthquakes should be the same as those of shallower ones if the velocity in the deeper part of the seismic layer is as low as that in the shallower part of it. Thus they concluded that the seismic layer where these deeper earthquakes occurred is no longer a low-velocity layer, but a high- or normal-velocity layer where gabbro or basalt that constitutes a main layer of the oceanic crust transformed to eclogite.

\section{A Non Double-Couple Earthquake}

\subsection{Focal mechanism}

Figure 3(a) shows P-wave first-motion distribution of event 1 that occurred on Feb. 10, 1987 and that is indicated by a thick arrow in Fig. 2. Clearly this is not a double-couple event. A compressional area on the focal sphere is limited and is at only one side. A fault-plane solution of event 2 (M3.9) indicated by a thin arrow in Fig. 2 that occurred $15 \mathrm{~h}$ after event 1 and very close to it in space is also shown in Fig. 3(b) to compare focal mechanisms of these two earthquakes. Since event 2 is a double-couple source, we can reject a possibility that the non double-couple mechanism of event 1 is due to the effect of the velocity structure assumed. Initial $\mathrm{P}$ waveforms at several stations are shown in Fig. 4(a). Polarities of initial $P$ waves are very clear.

Vol. 41, No. 4, 1993 

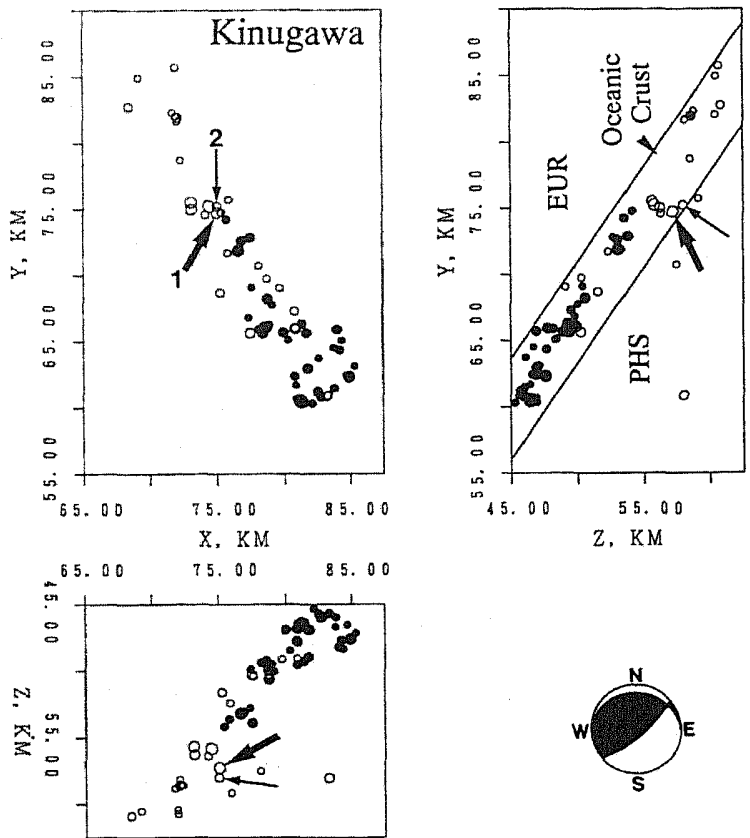

Fig. 2. Hypocenters of relocated earthquakes with magnitude greater than or equal to 3.0 in the Kinugawa cluster, southwestern Ibaraki. Top-left: Epicentral distribution. Top-right: Depth distribution along NS cross section. Bottom-left: Depth distribution along EW cross section. Thrust earthquakes with NW-SE $P$ axes and of which nodal planes dip northward at a low angle are shown by solid circles. An example of such a fault-plane solution is shown at the bottom-right. Equal-area projection of the lower hemisphere of the focal sphere is used. Open circles represent earthquakes with other mechanisms. The non double-couple earthquake is indicated by a thick arrow (event 1). A thin arrow (event 2) indicates a normal-faulting earthquake that is the largest aftershock of the non double-couple earthquake occurring $15 \mathrm{~h}$ later. The origin of coordinates $(x, y)$ is located at $139.0^{\circ} \mathrm{E}, 35.5^{\circ} \mathrm{N}$.

One may consider that event 1 occurred in a localized low-velocity region and that such anomalous first motions of event 1 can be produced by refracted first arrivals whose raypaths were bent by a velocity contrast located between the two events. However, it is implausible that the event in the low-velocity region, if occurred, caused after shocks in the surrounding high- or normal-velocity region. Furthermore, since the largest or the nearest aftershocks are about $1 \mathrm{~km}$ or $0.5 \mathrm{~km}$ from the mainshock, respectively, and frequencies of first motions of the mainshock at eastern stations HAS, NMT, and YST are about $2-6 \mathrm{~Hz}$, wavelengths of the initial $P$ waves are about $1-3 \mathrm{~km}$ if the velocity is $6 \mathrm{~km} / \mathrm{s}$. We cannot assume a plane-wave incidence at the velocity boundary, because the wavelength is comparable or longer than the distance between the source and the velocity boundary. Thus raypaths of initial waves may not be largely 


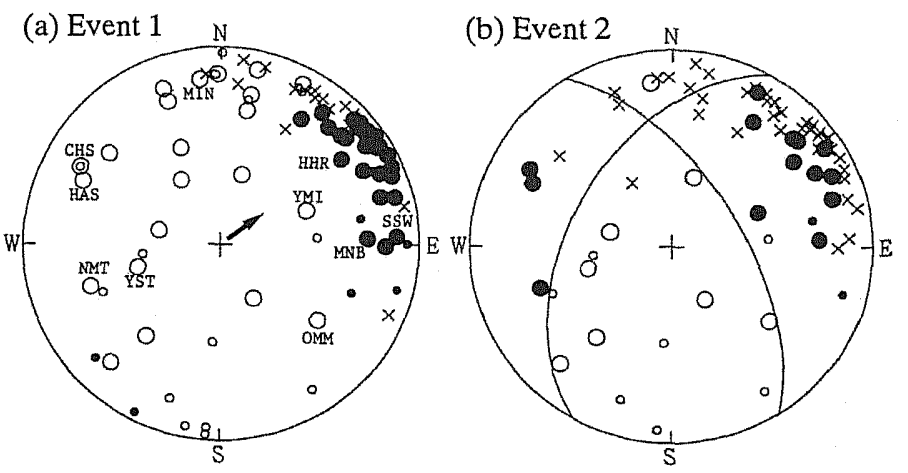

Fig. 3. (a) Focal mechanisms of the non double-couple earthquake (event 1, M4.6, $z=57 \mathrm{~km}$ ). An arrow on the focal sphere of event 1 indicates the direction to the triggered double-couple event whose fault plane is shown in Fig. 6. This fault plane is parallel to the one of the fault planes of event 2, which dips east-northeastward. Note that the center of the compressional area on the focal sphere of event 1 is approximately situated in the direction of the arrow. (b) Focal mechanisms of the nearby normal-faulting earthquake (event 2, M3.9, $z=58 \mathrm{~km}$ ) which occurred very close to event 1 . A fault-plane solution is also shown. Open and solid circles in focal spheres represent dilatational and compressional first motions, respectively. Large and small circles represent data of NIED and JMA, respectively. Note that rays to all stations emanated upward.

deflected by the velocity boundary even if it exists. This idea is supported by observational facts that all earthquakes in the subducting low-velocity oceanic crusts are double-couple sources (Hurukawa and Imoto, 1990, 1992) and raypaths of these events were not significantly deflected by velocity boundaries between the oceanic crusts and the surrounding mantle.

Figure 4(b) shows waveforms including both $\mathrm{P}$ and $\mathrm{S}$ waves at several stations. Clearly amplitudes of $S$ waves of event 1 are large. Amplitude ratios of $P$ and $S$ waves are almost similar in both events. This means that the non double-couple earthquake emanated not only compressional waves but also shear waves.

Figure 5 shows two possible solutions of the non double-couple earthquake. First, an eyeball-type solution is shown in Fig. 5(a). Since the compressional area on the focal sphere is limited at only one side, we draw a nodal plane of only one cone of which vertical angle is $90^{\circ}$ and its dip angle is $5^{\circ}$. We name this mechanism an eyeball type, because a conventional cone type has two cones on the focal sphere. Second, a conetype solution is shown in Fig. 5(b). Since two compressional $\mathrm{P}$ waves are observed at a southwestern part of the focal sphere, it is possible to interpret the non double-couple earthquake as a cone-type event as well as eyeball-type one. Its vertical and dip angles are $78^{\circ}$ and $10^{\circ}$, respectively. A number of inconsistent data is two in this solution and is the same as that in the eyeball-type solution. Thus we cannot tell which solution is better only from P-wave initial motions. Clearly the volume contraction is predominant in the non double-couple earthquake, because a total compressional area on the focal

Vol. 41, No. 4, 1993 

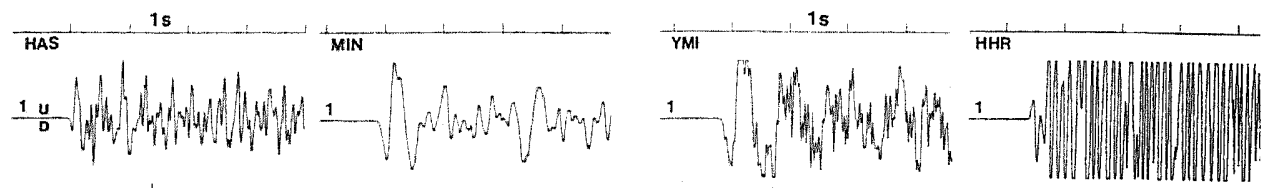

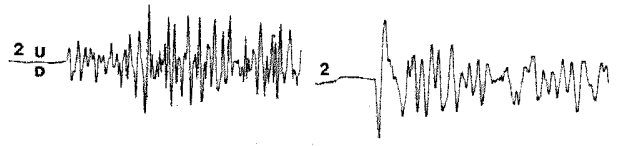
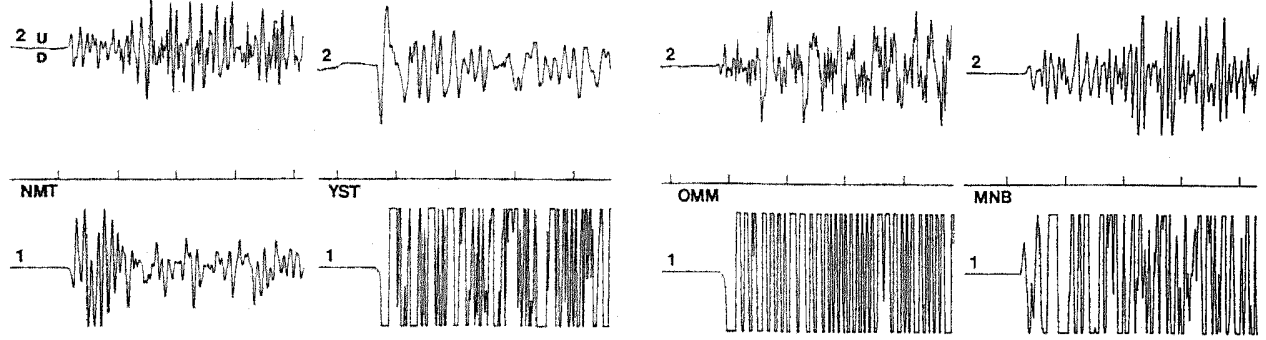

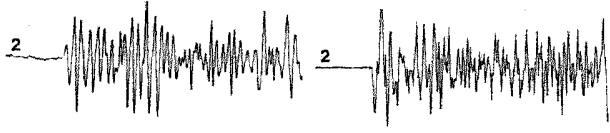

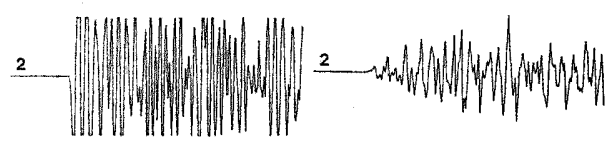

(a)
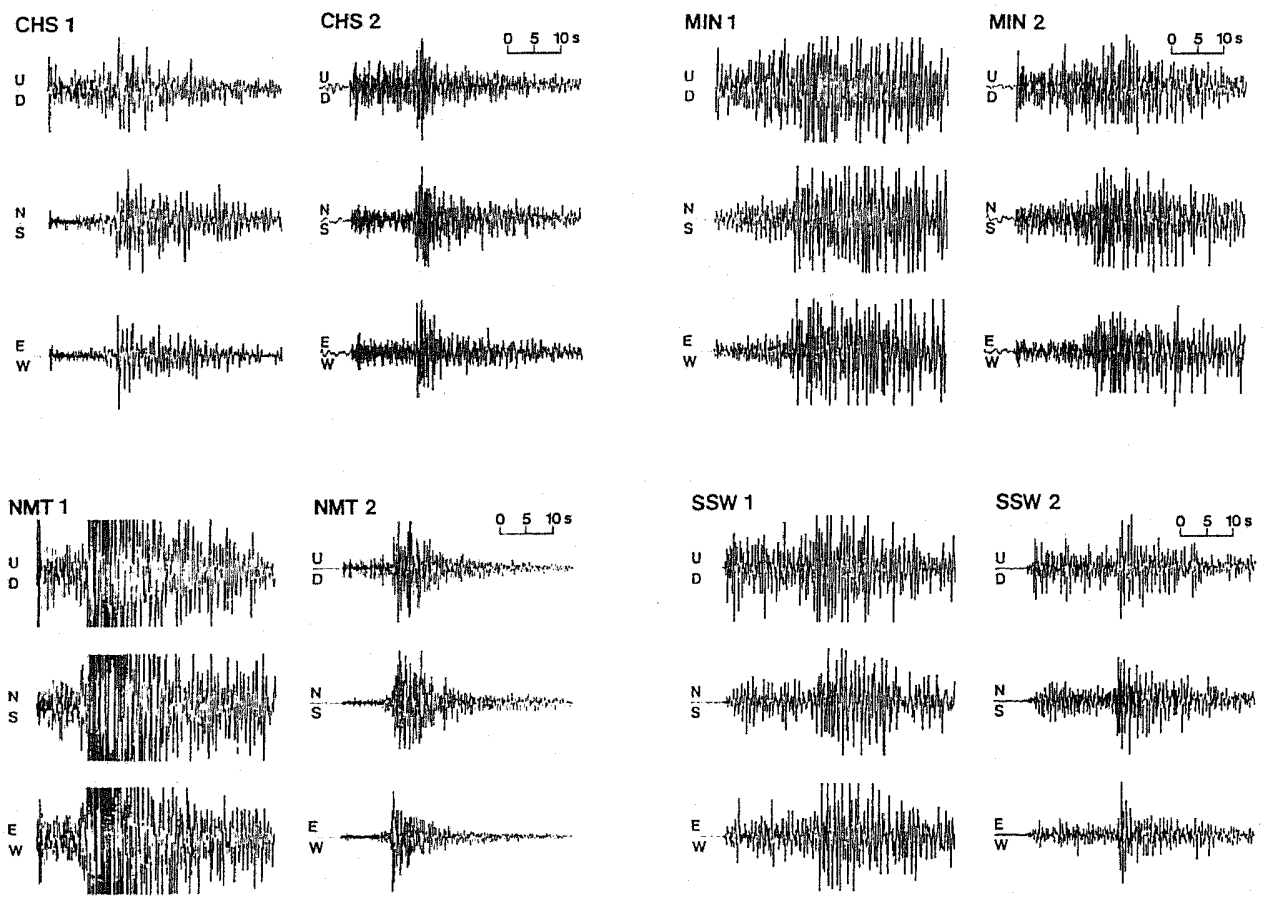

(b)

Fig. 4. Examples of waveforms of two earthquakes, events 1 and 2, at several NIED stations shown in Fig. 3(b). (a) Vertical-component seismograms of $P$ waves. (b) Three-component waveforms containing $\mathrm{P}$ and $\mathrm{S}$ waves. 
(a) Eyeball Type

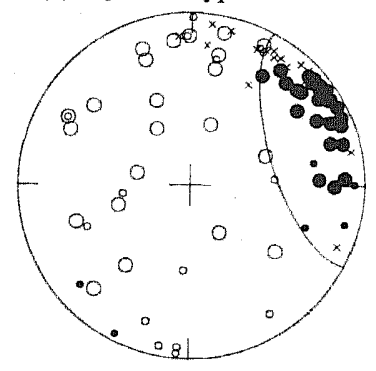

(b) Cone Type

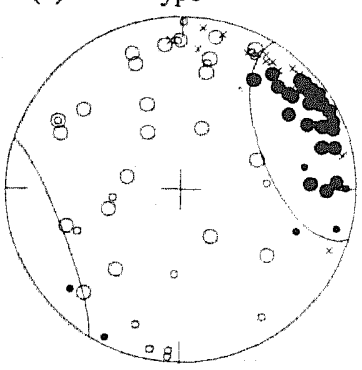

Fig. 5. Two possible solutions for the non double-couple earthquake (event 1). (a) Eyeball-type solution. A dip angle of a principal axis of the cone is $5^{\circ}$ and its vertical angle is $90^{\circ}$. (b) Cone-type solution. A dip angle of a principal axis of the cone is $10^{\circ}$ and its vertical angle is $78^{\circ}$.
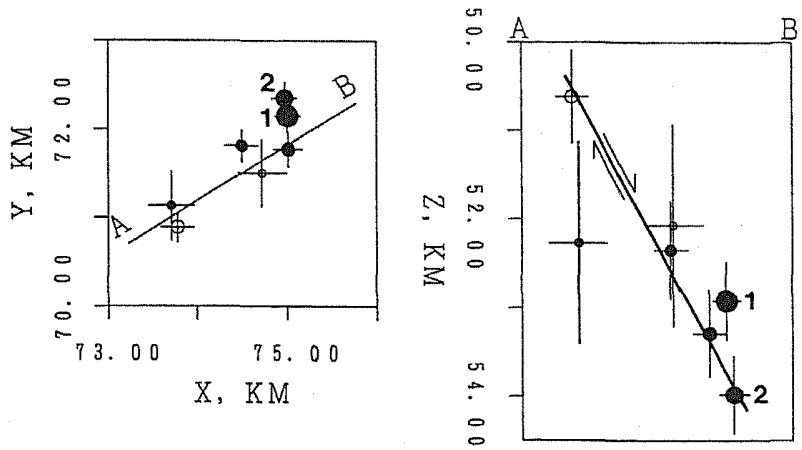

Fig. 6. Relocated hypocenters of the non double-couple earthquake (event 1) and its aftershocks. Left: Epicentral distribution. Right: Cross section along line A-B. Standard errors of hypocenters are indicated by bars. Events 1 and 2 are the same earthquakes as events 1 and 2 in Fig. 2, respectively. Solid circles represent non double-couple and normal-faulting earthquakes. Open circles represent earthquakes of other types. An expected fault plane of the double-couple earthquake triggered by the gabbro-eclogite transformation is shown by a thick line. Arrows indicate relative sense of displacement. Note that hypocenters are different from those in Fig. 2. Since a few events are relocated in this figure using a smaller number of stations than that in Fig. 2, the relative locations are better, whereas the absolute locations are worse than those in Fig. 2.

sphere is much smaller than a half of the total surface area of the focal sphere in both solutions.

\subsection{Aftershocks}

Aftershocks followed the non double-couple earthquake. Using a method of modified joint hypocenter determination (Hurukawa and Imoto, 1992), we relocated 
the non double-couple earthquake and its aftershocks including events with magnitude smaller than 3.0 to know their relative hypocenters accurately. We used 11 stations where more than 2 events were observed within an accuracy of $0.1 \mathrm{~s}$. Figure 6 shows relocated hypocenters. Although we could not obtain their focal mechanisms of aftershocks uniquely because of their small sizes except the largest aftershock (event 2) shown in Fig. 3(b), many of them are normal-faulting earthquakes. They distribute along a belt dipping east-northeastward with a dip angle of about $60^{\circ}$. Clearly this seismic belt is almost parallel to one of the nodal planes of event 2 shown in Fig. 3(b). The direction to the compressional area of the non double-couple event is also almost parallel to the strike of the aftershock belt. Thus the aftershock activity suggests that the mainshock of these aftershocks is a normal-faulting earthquake.

\section{Source Mechanism of the Non Double-Couple Earthquake}

We propose a source mechanism of the non double-couple earthquake that explains observational facts on it. A schematic illustration of the source mechanism is shown in Fig. 7. First, the sudden volume contraction happens, which is probably caused by a phase transformation. Second, it develops large shear stress in the material surrounding the contracting volume and triggers a normal-faulting earthquake immediately. Finally,
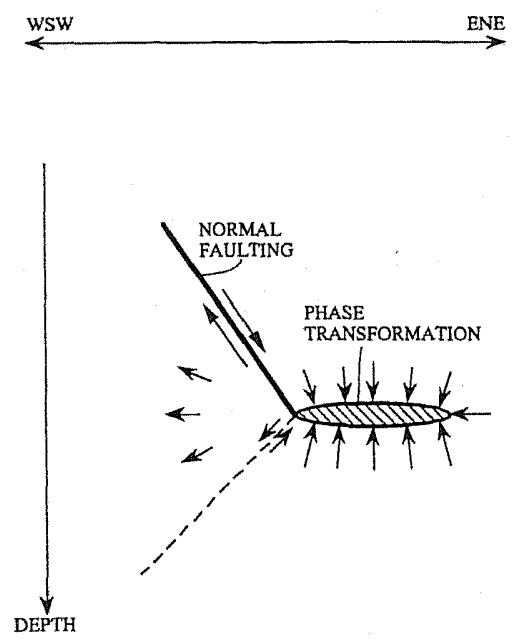

Fig. 7. A schematic illustration of the source process of the non double-couple earthquake. First, the phase transformation shown by a shaded ellipse occurred. Second, immediately after the phase transformation, the normal-faulting earthquake shown by a solid line was triggered by the phase transformation at its west-southwestern edge. Polarities of initial $P$ waves are shown by arrows. Long arrows indicate relative sense of displacement. Since the time difference of these two events is very small comparing a period of observed seismic waves, observed initial $P$ waves are those of the phase transformation and normal-faulting earthquake at east-northeastern and west-southwestern stations, respectively. A broken line indicates a nodal plane of P-wave polarities. 
aftershocks of the non double-couple event occurred along the fault plane of the triggered normal-faulting event. This model can explain the eyeball-type solution of the P-wave initial motions shown in Fig. 5(a) very well, because an expected vertical angle of a cone is $90^{\circ}$ and is same as the observed one. Compressional initial motions of the non double-couple earthquake are explained by initial motions of the triggered event, because its expected fault plane is located west-southwest of the non double-couple event, which is almost the same direction to stations with compressional initial motions. The observed strong shear waves were radiated by the triggered normal-faulting earthquake. Although excitation of $\mathrm{S}$ waves is well explained in the cone-type model without an additional triggered double-couple event, it cannot explain the aftershock distribution without the triggered double-couple event.

\section{Gabbro-Eclogite Transformation}

There are several possibilities that cause the non double-couple earthquake, that is the sudden volume contraction. They are 1) gabbro-eclogite transformation, 2) dehydration of hydrous minerals and 3) vitrification of minerals. Here we discuss gabbro-eclogite transformation, because the focal depth of the event is $57 \mathrm{~km}$ and is very close to the depth of the gabbro-eclogite transformation.

Since the non double-couple earthquake is located at the boundary between the low- and high-velocity oceanic crusts, this event seems to have been caused by the phase transformation from gabbro to eclogite. Since about $80 \%$ area of a focal sphere of this event is dilatational, it implies a sudden volume contraction. It is well known that gabbro transforms to eclogite at high temperature and high pressure in laboratory experiments (Ringwood and Green, 1966; Ito and Kennedy, 1971; Ahrens and Schubert, 1975). Gabbro in oceanic crusts is expected to transform to eclogite when it subducts into the mantle (Ringwood and Green, 1966; Ahrens and Schubert, 1975). The gravitational body force associated with this relatively cool and dense eclogitic layer provides a part of the driving mechanism for the mantle flow field (Ringwood and Green, 1966; Ahrens and Schubert, 1975; Pennington, 1983). When gabbro subducts deeply at metastability, this transformation proceeds very rapidly because of pressure beyond equilibrium. This volume contraction may generate a seismic shock in the same way as the olivine-spinel transformation expected in laboratory experiments (Dennis and Walker, 1965; Sung and Burns, 1976; Ringwood, 1976).

Strictly speaking, the gabbro-eclogite transformation is not a phase transformation of one mineral like the olivine-spinel transformation, but it consists of phase transformations of several minerals, such as [olivine, plagioclase, pyroxene]-[garnet, pyroxene]. It will take a long time and a wide range of pressure $(0.4-1.0 \mathrm{GPa})$ at a fixed temperature for gabbro to change to eclogite completely (e.g., Shimada, 1967). However, if a mineral that constitutes gabbro changes another mineral with higher density, for example such as first appearance of garnet, within a short time, this phase change will emanate a seismic wave. More possibly it will nucleate anticracks in metastable state of stress conditions (Kirby, 1987; Green et al., 1992), triggering faulting. Since it occurs as a part of the gabbro-eclogite transformation, we describe that the gabbro-eclogite transformation generates a seismic shock in this paper.

Vol. 41, No. 4, 1993 
Hori (1990) analyzed upper mantle earthquakes occurring beneath the western and central Japan. He found that the subducting oceanic crust of the PHS plate remained in a gabbroic phase without transformation to eclogitic rocks at depths down to about $60 \mathrm{~km}$ along the entire northern boundary of the PHS plate. Our result is in good agreement with his results. On the other hand, the oceanic crust of the PAC plate that directly contacts with the overriding PHS plate is still a low-velocity layer at least until 70-80 km (Hurukawa and Imoto, 1990, 1992). Therefore we can suppose the phase transformation in the oceanic crust of the PAC plate in the Kanto district takes place at deeper depth than that in the oceanic crust of the PHS plate there. This is easily explained by the faster convergent rate and older age of the PAC plate than those of the PHS plate. The temperature of the PAC plate is colder than that of the PHS plate.

\section{Discussion}

Figure 8(a) shows first-motion distribution of event 1 at stations outside Japan reported in the bulletin of International Seismological Centre (ISC). All these waves emanated downward. Although quality of ISC data is worse than that of NIED and JMA data, 4 among 5 stations show dilatational initial motions. Figure 8 (b) shows a seismogram of WB2 station at Warramunga array, Australia. The initial motion of the $P$ wave is clearly down. It was insufficient to identify a source type of the non double-couple event only from Fig. 3(a) if there is no spherical symmetry of a radiation pattern. However, combining the two distributions of first motions of upgoing and downgoing rays in Figs. 3(a) and 8(a), we can rule out a possibility that this is a single-force event.

a)
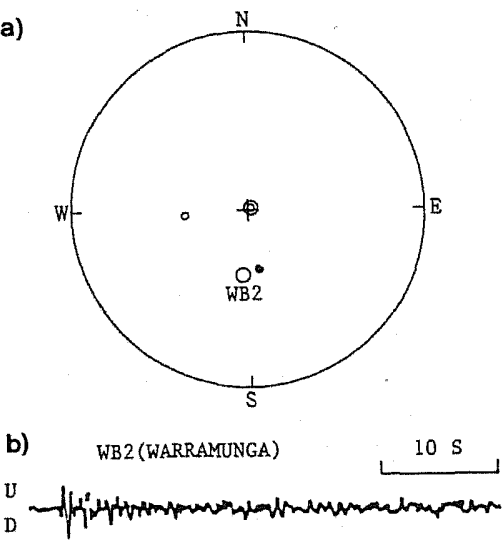

Fig. 8. (a) First-motion distribution of the non double-couple earthquake (event 1) at stations reported in the ISC bulletin except Japanese stations. Open and solid circles in the focal sphere represent dilatational and compressional first motions, respectively. Large and small circles represent reading ranks iP and $\mathrm{P}$, respectively. Note that rays to all stations emanated downward. (b) Verticalcomponent seismogram of event 1 at WB2 station, Warramunga array, Australia. 
a)
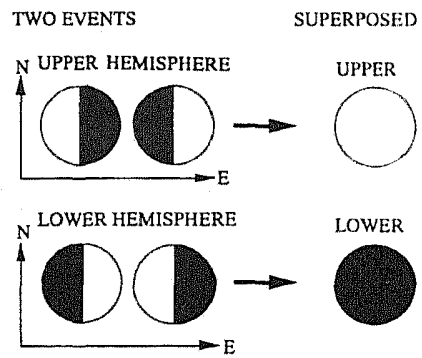

b)

TWO EVENTS SUPERPOSED

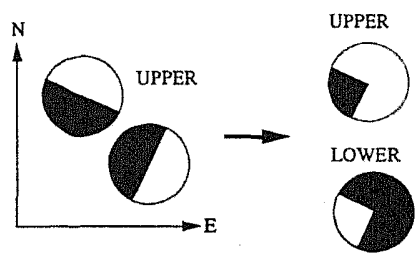

c) TWO EVENTS

SUPERPOSED

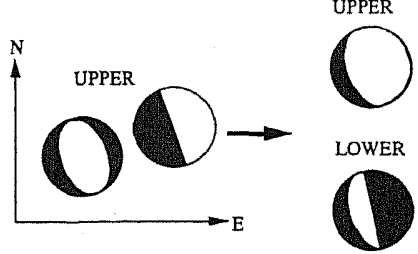

Fig. 9. A schematic illustration of mechanism diagrams of superposed event with two double-couple events with different mechanisms that occurred simultaneously and closely. Since there is no spherical symmetry of a radiation pattern of a superposed event, we should plot polarities of upgoing and downgoing rays separately on upper and lower hemispheres, respectively. (a) Simplest case: Two events occurred separately in the east-west direction and simultaneously. Nodal planes of each event are horizontal and vertical with NS direction. However, their mechanisms are different from each other. (b) Superposition of two events of which strikes of vertical nodal planes are not parallel. (c) Superposition of following two events. One is a normal-faulting event of which $T$ axis direct WSW-ENE. The other is an event with a horizontal and vertical nodal planes of which strike is NNW-SSE and its east side subsides.

In the same manner, we can also reject a possibility that this is a composite event with two double-couple earthquakes with different mechanisms, because a dilatational area on the focal sphere is more than several times larger than a compressional one. Figure 9 shows schematic mechanism of superposed event with two double-couple events with different mechanisms that occurred simultaneously and closely. Since there is no spherical symmetry of a radiation pattern of a superposed event, we should plot polarities of upgoing and downgoing rays separately on upper and lower hemispheres, respectively.

Vol. 41, No. 4, 1993 
Figure 9(a) represents a simplest case. Two events occurred separately in the east-west direction and simultaneously. Nodal planes of each event are horizontal and vertical with NS direction. However, their mechanisms are different from each other. In this case, superposed event shows a mechanism of a single force. In order to have a small part of a compressional area on the upper focal hemisphere, we should superpose two events of which strikes of vertical nodal planes are not parallel as shown Fig. 9(b). In this case, however, a compressional area is fan-shaped and is inconsistent with the observed mechanism. Another way to have a compressional area in west-southwestern part of the upper focal hemisphere is to combine the following two events shown in Fig. 9(c). One is a normal-faulting event of which $T$ axis direct WSW-ENE. The other is an event with a horizontal and vertical nodal planes of which strike is NNW-SSE and its east side subsides. In this case, however, a compressional area is crescent-shaped and is also inconsistent with the observed mechanism. As shown in these examples, dilatational and compressional areas on the focal sphere of a composite even with two double-couple earthquakes should be equal.

Another important phase transformation, olivine-spinel, takes place in the upper mantle. A depth of this phase transformation in a downgoing slat defines stress field inside the slab, and this phase transformation is a possible energy source for deep earthquakes (Dennis and Walker, 1965; Sung and Burns, 1976; Turcotte and Schubert, 1971). Our suggestions of the occurrence of the gabbro-eclogite transformation earthquake in the metastable field and of its triggering a double-couple earthquake support a possibility that the olivine-spinel transformation in the mantle might induce shear failure (Kirby, 1987; Meade and Jeanloz, 1989; Green and Burnley, 1989; Green et al., 1990, 1992; Burnley et al., 1991; Kirby et al., 1991). Although large deep earthquakes have no significant isotropic component (Kawakatsu, 1991), our result suggests importance to study source mechanisms of small deep earthquakes in detail.

We thank B. Kennett for kindly sending us a seismogram of WB2 station in Australia. We also thank M. Shimada and H. Kawakatsu for their useful discussions and comments. We appreciate comments of the associate editor and referees.

\section{REFERENCES}

Ahrens, T. J. and G. Schubert, Gabbro-eclogite reaction rate and its geophysical significance, Rev. Geophys. Space Phys., 13, 383-400, 1975.

Burnley, P. C., H. W. Green, and D. J. Prior, Faulting associated with the olivine to spinel transformation in $\mathrm{Mg}_{2} \mathrm{GeO}_{4}$ and its implications for deep-focus earthquakes, J. Geophys. Res., 96, 425-443, 1991.

Dennis, J. G. and C. T. Walker, Earthquakes resulting from metastable phase transitions, Tectonophysics, 2, 401-407, 1965.

Green, H. W. and P. C. Burnley, A new self-organizing mechanism for deep-focus earthquakes, Nature, 341, 733-737, 1989.

Green, H. W., T. E. Young, D. Walker, and C. H. Scholz, Anticrack-associated faulting at very high pressure in natural olivine, Nature, 348, 720-722, 1990.

Green, H. W., C. H. Scholz, T. N. Tingle, T. E. Young, and T. A. Koczynski, Acoustic emissions 
produced by anticrack faulting during the olivine spinel transformation, Geophys. Res. Lett., 19, 789-792, 1992.

Hamada, K., M. Ohtake, Y. Okada, S. Matsumura, and H. Sato, A high quality digital network for microearthquakes and ground tilt observations in the Kanto-Tokai area, Japan, Earthq. Predict. Res., 3, 447-469, 1985.

Hori, S., Seismic waves guided by untransformed oceanic crust subducting into the mantle: the case of the Kanto district, central Japan, Tectonophysics, 176, 355-376, 1990.

Hurukawa, N. and M. Imoto, Fine structure of an underground boundary between the Philippine Sea and Pacific plates beneath the Kanto district, Japan, Zisin (J. Seismol. Soc. Jpn.), 43, 413-429, 1990 (in Japanese with English abstract).

Hurukawa, N. and M. Imoto, Subducting oceanic crusts of the Philippine Sea and Pacific plates and weak-zone-normal compression in the Kanto district, Japan, Geophys. J. Int., 109, 639-652, 1992.

Ishida, M., Geometry and relative motion of the Philippine Sea plate and Pacific plate beneath the Kanto-Tokai district, Japan, J. Geophys. Res., 97, 489-513, 1992.

Ito, $\mathrm{K}$. and G. C. Kennedy, An experimental study of the basalt-garnet granulite-eclogite transition, in The Structure and Physical Properties of the Earth's Crust, ed. J. G. Heacock, pp. 303-314, Am. Geophys. Union, Washington, D.C., 1971.

Kasahara, K., Patterns of crustal activity associated with the convergence of three plates in the Kanto-Tokai area, central Japan, Rep. NRCDP, 35, 33-137, 1985 (in Japanese with English abstract).

Kawakatsu, H., Insignificant isotropic component in the moment tensor of deep earthquakes, Nature, 351, 50-53, 1991.

Kirby, S. H., Localized polymorphic phase transformations in high-pressure faults and applications to the physical mechanism of deep earthquakes, J. Geophys. Res., 92, 13789-13800, 1987.

Kirby, S. H., W. B. Durham, and L. A. Stern, Mantle phase changes and deep-earthquake faulting in subducting lithosphere, Science, 252, 216-225, 1991.

Meade, C. and R. Jeanloz, Acoustic emissions and shear instabilities during phase transformations in $\mathrm{Si}$ and Ge at ultrahigh pressures, Nature, 339, 616-618, 1989.

Nakamura, K. and K. Shimazaki, The Sagami and Suruga troughs and plate subduction, Kagaku, 51, 490-498, 1981 (in Japanese).

Okada, Y. and K. Kasahara, Earthquake of 1987, off Chiba, central Japan and possible triggering of eastern Tokyo earthquake of 1988, Tectonophysics, 172, 351-364, 1990.

Pennington, W. D., Role of shallow phase changes in the subduction of oceanic crust, Science, 220, 1045-1047, 1983.

Ringwood, A. E., Phase transformations in descending plates and implications for mantle dynamics, Tectonophysics, 32, 129-143, 1976.

Ringwood, A. E. and D. H. Green, An experimental investigation of the gabbro-eclogite transformation and some geophysical implications, Tectonophysics, 3, 383-427, 1966.

Shimada, M., An experimental study of the basalt-eclogite transition, Spec. Contrib. Geophys. Inst. Kyoto Univ., 7, 211-217, 1967.

Sung, C. M. and R. G. Burns, Kinetics of high-pressure phase transformation: implications to the evolution of the olivine-spinel transition in the downgoing lithosphere and its consequences on the dynamics of the mantle, Tectonophysics, 31, 1-32, 1976.

Turcotte, D. L. and G. Schubert, Structure of the olivine-spinel phase boundary in the descending lithosphere, J. Geophys. Res., 76, 7980-7987, 1971.

Vol. 41, No. 4, 1993 